\title{
Characterization of novel genetic alterations in salivary gland secretory carcinoma
}

\author{
Kiyong $\mathrm{Na}^{1,2} \cdot$ Juan C. Hernandez-Prera ${ }^{3} \cdot$ Jae-Yol Lim $^{4} \cdot$ Ha Young Woo ${ }^{1} \cdot$ Sun Och Yoon $\mathbb{D}^{1,3}$
}

Received: 25 June 2019 / Revised: 11 November 2019 / Accepted: 11 November 2019 / Published online: 10 December 2019

(c) The Author(s) 2019. This article is published with open access

\begin{abstract}
Secretory carcinoma is a salivary gland tumor with a characteristic chromosomal translocation that results in an ETV6NTRK 3 fusion gene. Secretory carcinoma shows relatively frequent rates of lymph-node metastasis and tumor recurrence and has a characteristic histology. Except for the ETV6 translocation, genomic alterations in secretory carcinoma have not been reported. In the present study, we characterized the novel recurrent genetic mutations of secretory carcinoma. On the basis of histology, immunohistochemistry, and ETV6 gene break-apart fluorescence in situ hybridization assays, 22 tumors were classified as secretory carcinomas (19 ETV6 translocation-positive and 3 ETV6 translocation-negative secretory carcinomas) and their clinicopathologic characteristics were reviewed. Targeted deep sequencing analyses were performed on 20 secretory carcinomas (17 ETV6 translocation-positive and 3 ETV6 translocation-negative secretory carcinomas) to investigate their genetic alterations. The $\mathrm{A} 16 \mathrm{~V}(\mathrm{C} \rightarrow \mathrm{T})$ mutation in PRSS1, which encodes a cationic trypsinogen and has a mutation associated with hereditary pancreatitis and pancreatic adenocarcinoma, was observed in 40\% (8/20) (7/17 of ETV6 translocation-positive and 1/3 of ETV6 translocation-negative secretory carcinomas). Pathogenic variants of $M L H 1$, MUTYH, and STK11 were also identified. Variants of uncertain significance included mutations in KMT5A. These novel characteristic genetic alterations may advance current understandings of secretory carcinoma tumorigenesis and progression, leading to improved diagnoses and treatment strategies.
\end{abstract}

\section{Introduction}

Secretory carcinoma is a recently described salivary gland neoplasm characterized by the chromosomal translocation $\mathrm{t}(12 ; 15)(\mathrm{p} 13 ; \mathrm{q} 25)$, which results in the ETV6-NTRK3

Supplementary information The online version of this article (https:// doi.org/10.1038/s41379-019-0427-1) contains supplementary material, which is available to authorized users.

$\triangle$ Sun Och Yoon

soyoon@yuhs.ac

1 Department of Pathology, Yonsei University College of Medicine, Yonsei University Health System, Severance Hospital, Seoul, South Korea

2 Department of Pathology, College of Medicine, Kyung Hee University, Seoul, South Korea

3 Department of Anatomic Pathology, H. Lee Moffitt Cancer Center and Research Institute, Tampa, FL, USA

4 Department of Otorhinolaryngology, Yonsei University College of Medicine, Yonsei University Health System, Seoul, South Korea fusion gene. This gene is identical to the one found in secretory carcinoma of the breast, infantile fibrosarcoma, and acute myeloid leukemia [1-3].

Since the description of secretory carcinoma as a new disease entity, several studies have reported the clinicopathologic features of secretory carcinoma that allow for its differential diagnosis from other subtypes of salivary gland tumors, such as acinic cell carcinoma, adenocarcinoma-not otherwise specified, low-grade mucoepidermoid carcinoma, and intraductal carcinoma, or so-called low-grade cribriform cystadenocarcinoma. The histologic features of secretory carcinoma include a variety of architectural growth patterns, the presence of intracytoplasmic vacuoles, mucin-like and colloid-like eosinophilic secretions, and a lack of intracytoplasmic periodic acid-Schiff ${ }^{+}\left(\mathrm{PAS}^{+}\right)$zymogen granules. Immunohistochemistry analyses have shown that most secretory carcinomas are positive for S100 and mammaglobin and negative for DOG1 [2, 4-15]. Secretory carcinoma reveals relatively frequent rates of lymph node metastasis in as many as $25 \%$ of cases at presentation [2]. This tumor usually shows indolent clinical behaviors; however, 
aggressive courses, such as recurrence and death of disease, are also reported in some cases [1, 2, 4, 16-18].

Apart from the ETV6 gene translocation, little is known about genomic alterations in secretory carcinoma. Therefore, further studies of the novel recurrent genetic alterations in secretory carcinoma are needed. In this study, we characterized the genetic alterations in secretory carcinoma through targeted deep sequencing analyses to detect novel recurrent somatic mutations.

\section{Materials and methods}

\section{Case selection}

The database of Severance Hospital Cancer Registry Data (Seoul, South Korea) was searched to identify secretory carcinoma candidates from salivary gland tumors originally diagnosed as acinic cell carcinoma, adenocarcinoma-not otherwise specified, various subtypes of adenocarcinoma, and mucoepidermoid carcinoma. Patients with other malignancies were not included. The tumors were from patients treated and monitored at the Yonsei University Health System Department of Otorhinolaryngology. Patient medical records, pathology reports, and clinical details were reviewed in accordance with the Eighth American Joint Committee on Cancer criteria [19]. The study was approved by the Severance Hospital Institutional Review Board (Protocol No. 42018-0816). Supplementary Fig. 1 shows a flowchart and details of the study.

After an initial screening of histology and clinical data, all cases of acinic cell carcinoma and adenocarcinoma not otherwise specified in salivary glands were selected for further screening. Two independent pathologists ( $\mathrm{KN}$ and SOY) reviewed all available stained slides by routine light microscopy and selected the most representative formalinfixed paraffin-embedded block for ancillary tests. Histologic classification followed the World Health Organization classification criteria [2]. Candidate cases were selected for ETV6 gene rearrangement fluorescence in situ hybridization (FISH) analyses on the basis of having lowgrade nuclear features with bubbly eosinophilic cytoplasm, no zymogen granules, a positive staining for $\mathrm{S} 100$ and/or mammaglobin, and a negative staining for DOG1 and P63. Twenty two of the reviewed cases were considered to be secretory carcinoma. Among them, 19 secretory carcinomas harbored ETV6 translocation and 3 secretory carcinomas lacked ETV6 translocation. These 3 ETV6 translocation-negative cases, which were originally diagnosed as acinic cell carcinoma, had a histology similar to that of secretory carcinoma in that they showed microcystic, tubular, and papillary cystic architectures, low-grade uniform nuclei, occasional small nucleoli, pinkish bubbly cytoplasm, lack of PAS+zymogen granules, and mucin-like and colloid-like eosinophilic secretions. They also displayed diffuse positive staining for both S100 and mammaglobin and negative staining for DOG1 and P63. These cases did not demonstrate features favoring low-grade mucoepidermoid carcinoma, such as squamoid differentiation or intracytoplasmic mucin. Also, the lack of micropapillary or sieve-like fenestrated architectures and the presence of invasive foci were different from typical histological features of low-grade salivary duct carcinoma [2]. Given their present histological features and immunophenotypes typical of secretory carcinoma, these 3 cases were included as secretory carcinoma as suggested [20].

During the review process, we also reviewed 36 acinic cell carcinoma cases. To further identify the characteristics of secretory carcinoma that distinguish it as a clinicopathologically distinct disease entity, we compared the clinical and histologic features of 22 secretory carcinomas with those of the 36 cases of acinic cell carcinoma.

\section{Tissue microarray preparation and immunohistochemistry}

To construct the tissue microarray, two different representative tumor areas per sample were selected, and $3 \mathrm{~mm}$ tissue cores were taken from formalin-fixed paraffinembedded donor tissue blocks and arranged in recipient tissue microarray blocks using a trephine apparatus. A Ventana Benchmark XT autostainer (Ventana Medical Systems, Inc, Tucson, AZ, USA) was used to perform immunohistochemistry analyses for mammaglobin (clone 31A5, 1:100; Cell Marque, Rocklin, CA, USA), S100 (clone Z0311, 1:2000; Dako, Glostrup, Denmark), DOG1 (clone SP31, Ready-to-Use; Cell Marque), p63 (clone M7317, 1:200; Dako), and androgen receptor (RTU, clone SP107; Cell Marque). The immunohistochemistry analyses were performed on $4 \mu \mathrm{m}$ thick sections prepared from the tissue microarray tissue blocks and representative formalin-fixed paraffin-embedded tissues when necessary, in accordance with standard protocols [21].

\section{Fluorescence in situ hybridization}

FISH was performed on representative formalin-fixed paraffin-embedded tissue sections using a commercially available ETV6 dual-color break-apart probe (07j77-001; Abbott Molecular, Des Plaines, IL, USA), as previously described [22]. Cells with the ETV6 rearrangements had split orange and green signals that were apart from each other. Tumors were considered to be positive for ETV6 if this rearrangement was found in $>15 \%$ of cells. 


\section{Targeted deep sequencing analyses}

All targeted deep sequencing analyses (including related experiments and genome analyses) were performed at Macrogen (Seoul, South Korea). A customized panel (Axen Cancer Master Panel, Macrogen) including 535 genes for $\mathrm{SNV} / \mathrm{InDel}, 54$ genes for fusions, and 1 promoter gene was designed and used for the targeted sequencing (See Supplementary Table 1 for the entire list of genes) of 20 secretory carcinoma samples (17 ETV6 translocation-positive and 3 ETV6 translocation-negative secretory carcinomas). Pairedend sequencing $(2 \times 150 \mathrm{bp})$ was performed using a NextSeq 500 sequencer (Illumina, San Diego, CA, USA). Genome analyses were performed to detect somatic short variants following GATK (Genome Analysis Toolkit) Best Practices [23]. The adapter sequences were removed using Cutadapt [24]. The raw sequence reads in FASTQ files were mapped to the UCSC hg19 human reference by using BWA-mem [25]. Poorly mapped reads with mapping quality values $<20$ were removed using Samtools [26]. Picard MarkDuplicates (http:// broadinstitute.github.io/picard) were used to exclude PCR artificial duplicates. Indel realignment and base quality score recalibration were performed using GATK, and the Mutect2 algorithm in the GATK was used to call somatic single nucleotide variants and indels [27]. False positive variant calls originating from oxoG artifacts were excluded. In addition, mutations with a variant allele frequency $<3 \%$ and a $100 \times$ total depth were excluded. Germline variants were excluded when the minor allele frequency was $\geq 5 \%$ in the Exome Aggregation Consortium (http://exac.broadinstitute.org/) or the Macrogen Korean Population Database [28]. The functional impacts of the variants were determined using SnpEff v4.3 and SnpSift with dbNSFP v2.9.3 [29-31]. Variants were further filtered using the following cut-off values: mutant allele count $<5$ and an allele frequency in the normal population (from dbSNP) $>0.1$ [32]. All remaining variants were manually inspected by sequence analysis experts using the Integrative Genomics Viewer [33]. The fusion genes were analyzed using an in-house script (Macrogen) that was able to discriminate plausible gene fusion events among the structural variations predicted by LUMPY [34] and UMI Error Correction Local App 1.0.0.1 (Illumia; https://support.illumina. com/downloads/umi-error-correction-local-app-documenta tion.html). Copy number variations were analyzed using an in-house script (Macrogen). The clinical significance of genetic variants was determined on the basis of the ClinVar variation report (https://www.ncbi.nlm.nih.gov/clinvar).

\section{Statistical analyses of patient survival}

The Kaplan-Meier method was used to analyze survival rates, and differences were compared using the log-rank test. Overall survival was measured from the date of diagnosis to the date of death or last follow-up. Disease-free survival was measured from the date of diagnosis to cancer recurrence, continuance of stable disease/partial remission/progressive disease without complete remission, or cancer-related death during the study period. Two-sided $P$ values $<0.05$ were considered statistically significant. Statistical analyses were conducted using IBM SPSS 23 software for Windows (IBM Corp, Armonk, NY, USA).

\section{Results}

\section{Histological features and clinical outcomes of secretory carcinoma}

The histopathologic and clinical features of the 22 secretory carcinoma cases are represented in Figs. 1 and 2 and summarized in Tables 1 and 2. The characteristics of the 36 acinic cell carcinoma cases are summarized for comparison and represented in Fig. 2 and Tables 1 and 2. Details are described in the Supplementary Appendix and Supplementary Figs 2 and 3.

Histologically, papillary cystic growth was the most common pattern observed in the secretory carcinoma cases (64\% [14/22]). The tumor cells showed low-grade uniform nuclei, occasional small nucleoli, and pinkish bubbly cytoplasm. $\mathrm{PAS}^{+}$zymogen granules were not observed, but mucin-like and colloid-like eosinophilic secretions were easily observed. All secretory carcinomas were diffusely stained for S100 in both the nuclei and cytoplasm, except for one case with focal expression. Mammaglobin expression presented in $91 \%$ (20/22) of the secretory carcinomas as a cytoplasmic staining pattern and showed diffuse expression in $77 \%$ (17/22). None of the secretory carcinomas showed diffuse expression of DOG1 or p63. The ETV6 gene rearrangement was noted in 86\% (19/22) in FISH analyses (Table 1). Cervical lymph node dissection was performed in 50\% (11/22) of patients with secretory carcinoma; among them, four had nodal metastasis. The American Joint Committee on Cancer tumor stage distribution of our series was I (14\% [3/22]), II (64\% [14/22]), and III (23\% [5/22]). The median follow-up for patients with secretory carcinoma was 46 months (range, 6-140 months). During the follow-up period, $32 \%$ (7/22) of patients experienced disease recurrence, including local (23\% [5/ $22])$, nodal (5\% [1/22]), and local and nodal disease (5\% [1/ 22]). The median interval period between surgery and recurrence was 24 months (range, 6-51 months). None of the patients died from disease during the follow-up period (Table 2). When comparing rates of disease-free survival between secretory carcinoma and acinic cell carcinoma patients, no statistical significance was observed (Supplementary Fig. 4). 


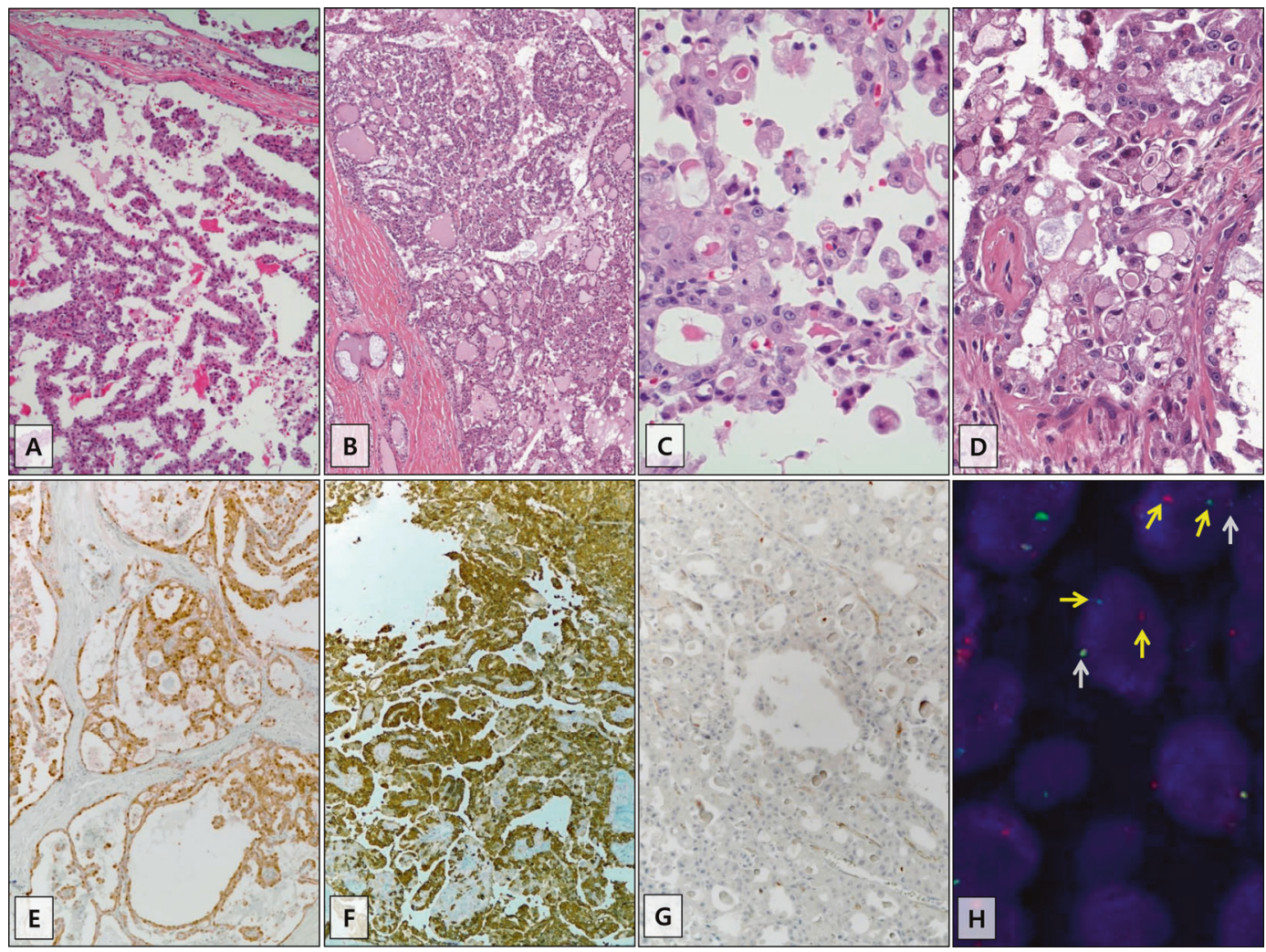

Fig. 1 Histopathological features of secretory carcinoma. Tumors frequently show papillary cystic (a) and microcystic (b) growth architectures. The tumor cells show low-grade uniform nuclei, occasional small nucleoli, and pinkish bubbly cytoplasm (c). Mucin-like and/or eosinophilic secretions are easily detected in tumors with microcystic growth patterns $(\mathbf{b}, \mathbf{d})$. The tumors showed expression of

\section{Status of gene alterations}

Twenty tumor tissue samples consisting of secretory carcinomas (17 ETV6 translocation-positive and 3 ETV6 translocation-negative secretory carcinomas) were subjected to targeted deep sequencing analyses. Genetic variants were selected for screening if they were pathogenic, likely pathogenic, of uncertain significance in the ClinVar variation report (https://www.ncbi.nlm.nih.gov/clinvar), and among those observed in human cancers (Fig. 3 and Supplementary Table 2).

In our series, four genes were identified as pathogenic or likely pathogenic. These included missense mutations and splice site mutations in PRSSI (c.47C >T; p.A16V), MLHI (c.1151T>A; p.V384D), MUTYH (c.934-2A>G; splice site), and STK11 (c.842C>T; p.P281L). The most commonly detected pathogenic variant was the mutation in the PRSS1 gene, which was detected in $40 \%(8 / 20 ; 7 / 17$ of ETV6 translocation-positive and $1 / 3$ of ETV6 translocationnegative secretory carcinomas). Mutations in $M L H 1$ and MUTYH were noted in secretory carcinoma $(n=2$ and 1 , respectively), and serine/threonine kinase 11 (STK11), a
S100 (e) and mammaglobin (f) and no expression of DOG1 (g). An ETV6 break-apart FISH assay showed a split of one red signal and one green signal per nucleus, indicative of ETV6 translocation $(\mathrm{H}$ : yellow arrow) with a fusion signal (H: gray arrow). The images in A through $\mathrm{G}$ were captured at $\times 100$ and $\times 400$ magnification.

gene associated with the phosphatidylinositol 3-kinase (PI3K) pathway, was observed $(n=1)$ [35]. As a variant of uncertain significance, KMT5A (c.290-3C >A; splice site) mutations were recurrently observed in $25 \%(5 / 20)$ of secretory carcinomas. Although rare, several variants of uncertain significance were noted in secretory carcinoma; these were mutations in PALB2 (c.2329G $>$ A; p.D777N), RET (c.2611G $>$ A; p.V871I), BRCA2 (c.6029T $>\mathrm{G} ;$ p. V2010G), $A P C$ (c.1276G >T; p.A426S), $N B N$ (c.505C $>$ T; p. R169C), and BRIPI (c.485G >A; p.R162Q) (Fig. 3). None showed a significant copy number alteration.

\section{Clinical implications of gene alterations}

The tested cases were divided into two groups. The cases were classified into the aggressive group ( 9 secretory carcinomas) if they had at least one of following features: the presence of lymph node metastasis, were classified as American Joint Committee on Cancer stage III, and/or had tumor recurrence during the observation period. The cases classified into the indolent group (11 secretory carcinomas) did not include any of the above-mentioned features. The 

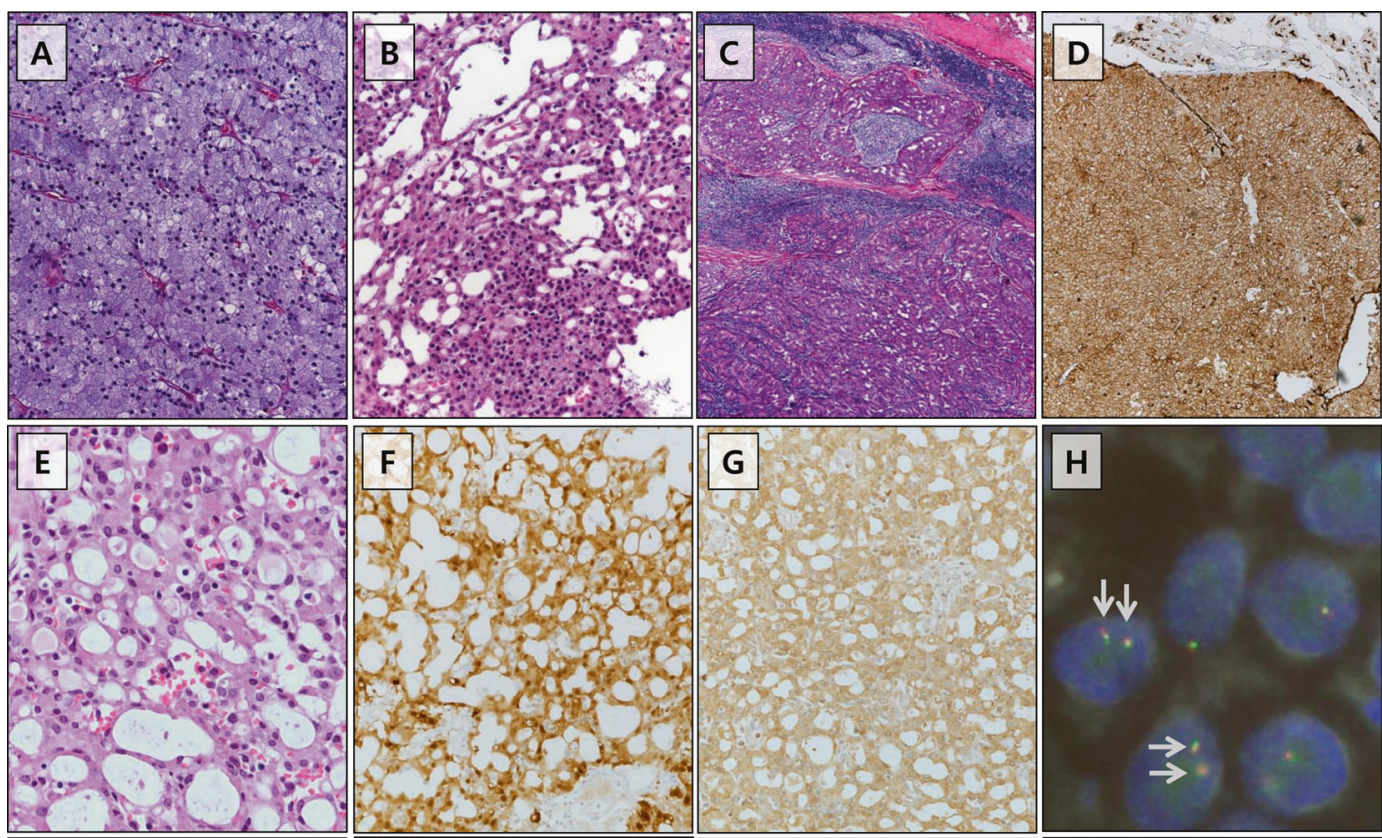
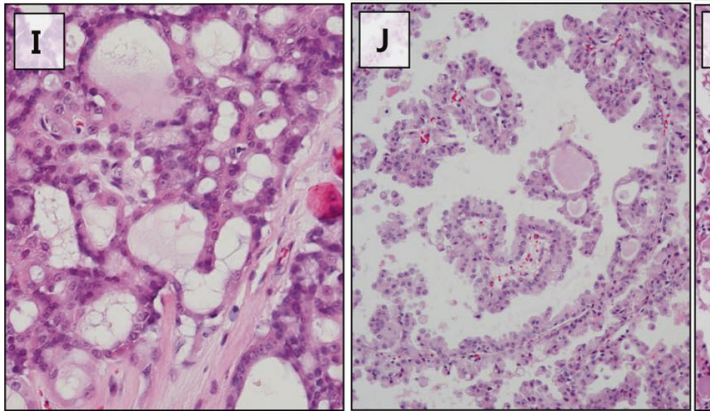

Fig. 2 Histologic features of acinic cell carcinoma and ETV6 translocation-negative secretory carcinoma. Features of typical acinic cell carcinoma or blue dot tumor (a). Microcystic acinic cell carcinoma showing focal zymogen granule-containing cells (b). The tumor stroma is sometimes lymphocyte predominant (c). Typical immunohistochemistry of acinic cell carcinoma showing DOG1 positivity (d). A case of ETV6 translocation-negative secretory carcinoma showing microcystic architecture without definite zymogen granules (E) and diffuse staining for S100 (f) and mammaglobin (g). The tumor shows an intact ETV6 gene by FISH. Most tumor nuclei show intact fusions (h, red and green signals; gray arrows). This case showed STK11 gene mutation. Another case of ETV6 translocation-

genetic alterations analyzed in each group are represented in Fig. 4.

The mutation frequency of PRSS1 was 56\% (5/9) in the aggressive group and 27\% (3/11) in the indolent group. Mutations in MLH1 and MUTYH genes are involved in DNA repair and the development of cancers, especially colorectal cancer (ClinVar; https://www.ncbi.nlm.nih.gov/ clinvar/) [36]. Mutations in these genes were only observed in the aggressive group. The KMT5A gene is involved in histone modification due to its function as a histone methyltransferase [37] (ClinVar; https://www.ncbi.nlm.nih. gov/clinvar/). Although a variant of uncertain significance, KMT5A was found to have a mutation rate of $44 \%$ negative secretory carcinoma showing microcystic architecture (i). This case revealed no remarkable genetic alteration. Another ETV6 translocation-negative secretory carcinoma showing variegated architectures of predominantly papillary cystic, partly microcystic architecture, and focally solid growth patterns $(\mathbf{j}-\mathbf{l})$. This case showed PRSS1 mutation. The tumor cells of those three ETV6 translocationnegative secretory carcinomas showed low-grade uniform nuclei, occasional small nucleoli, and pinkish bubbly cytoplasm $(\mathbf{e}, \mathbf{i}-\mathbf{k})$. Mucin-like and/or eosinophilic secretions are easily detected in tumors with microcystic growth patterns $(\mathbf{e}, \mathbf{i}, \mathbf{k})$. Further features of the three cases of ETV6 translocation-negative secretory carcinoma are summarized in Supplementary Fig. 3.

(4/9) in the aggressive group and $9 \%(1 / 11)$ in the indolent group.

\section{Results of RNA fusion gene analysis}

The RNA extracted from the formalin-fixed paraffinembedded tissues was severely degraded, and RNA quality was very low. Nevertheless, RNA fusion gene analyses detected several gene fusion types. The fusion variant of ETV6- NTRK3 was noted in 4 out of 17 ETV6 translocationpositive secretory carcinomas, which were defined by FISH assays. This fusion variant was not detected in any of the 3 ETV6 translocation-negative secretory carcinomas. 
Table 1 Histologic features of secretory carcinoma.

\begin{tabular}{|c|c|c|}
\hline Variables & $\begin{array}{l}\text { Secretory carcinoma } \\
(N=22)\end{array}$ & $\begin{array}{l}\text { cinic cell carcinoma } \\
V=36)\end{array}$ \\
\hline \multicolumn{3}{|l|}{ Gross appearance } \\
\hline Single-round & $15(68 \%)$ & $16(44 \%)$ \\
\hline Multi-lobulated & $7(32 \%)$ & $20(56 \%)$ \\
\hline \multicolumn{3}{|l|}{ Tumor border } \\
\hline Pushing & $14(64 \%)$ & $25(69 \%)$ \\
\hline Infiltrative & $8(36 \%)$ & $11(31 \%)$ \\
\hline \multicolumn{3}{|l|}{ Dominant growth pattern } \\
\hline Solid & $0(0 \%)$ & $29(81 \%)$ \\
\hline Microcystic & $6(27 \%)$ & $7(19 \%)$ \\
\hline Papillary cystic & $14(64 \%)$ & $0(0 \%)$ \\
\hline Cribrifrom & $2(9 \%)$ & $0(0 \%)$ \\
\hline \multicolumn{3}{|l|}{ Tumor stroma } \\
\hline Sclerosis & $22(100 \%)$ & $31(86 \%)$ \\
\hline Lymphocyte-rich & $0(0 \%)$ & $5(14 \%)$ \\
\hline \multicolumn{3}{|l|}{ Zymogen granule } \\
\hline Prominent & $0(0 \%)$ & $30(83 \%)$ \\
\hline Focally present & $0(0 \%)$ & $6(17 \%)$ \\
\hline Absent & $22(100 \%)$ & $0(0 \%)$ \\
\hline Lymphovascular invasion & $0(0 \%)$ & $2(6 \%)$ \\
\hline Perineural invasion & $2(9 \%)$ & $4(11 \%)$ \\
\hline \multicolumn{3}{|l|}{ Immunohistochemistry } \\
\hline DOG1 expression & 2 (9\%; focal) & $36(100 \% ; 36$ diffuse \\
\hline S100 expression & $22(100 \% ; 21$ diffuse and 1 focal $)$ & al) $0(0 \%)$ \\
\hline Mammaglobin expression & $20(91 \% ; 17$ diffuse and 3 focal $)$ & l) $0(0 \%)$ \\
\hline P63 expression & $0(0 \%)$ & $0(0 \%)$ \\
\hline \multicolumn{3}{|l|}{ ETV6 gene } \\
\hline Translocated & $19(86 \%)$ & Not done \\
\hline Not translocated & $3(14 \%)$ & \\
\hline
\end{tabular}

Single-event fusion variants were identified (including ETV6 with NTRK2, PAX5, or ABL1 and fusion scripts of LPP- KMT2A, QKI- NTRK2, NUP214- ABL1, and BRAF$M K R N 1)$ with a read depth below 5. Details are summarized in Supplementary Table 3.

\section{Discussion}

We characterized the novel recurrent somatic mutations in secretory carcinoma using targeted deep sequencing analyses. To our knowledge, no recurrent genomic alterations in secretory carcinoma, except for the ETV6 rearrangement, have been reported.

In our screening for secretory carcinoma candidates, we noted that zymogen granule-poor tumors that were initially diagnosed as acinic cell carcinoma constituted the largest source of secretory carcinomas, as reported in previous studies [4-14]. Although secretory carcinoma is the disease entity most commonly mimicked by acinic cell carcinoma $[2,38]$, we confirmed that secretory carcinoma had several distinct features. Clinically, patients with secretory carcinoma had relatively frequent lymph node metastasis. In our series, at least 4 out of $22(18.2 \%)$ secretory carcinomas were pathologically proven to be lymph node-positive. The rates of lymph node metastasis have been reported in as
Table 2 Clinicopathologic features and clinical outcomes of secretory carcinoma.

\begin{tabular}{|c|c|c|}
\hline Variables & $\begin{array}{l}\text { Secretory carcinoma } \\
(N=22)\end{array}$ & $\begin{array}{l}\text { Acinic cell } \\
\text { carcinoma }(N=36)\end{array}$ \\
\hline Median age (year) & $\begin{array}{l}34 \text { (mean, 36.5; } \\
\text { range, 6-78) }\end{array}$ & $\begin{array}{l}34 \text { (mean, 37.9; } \\
\text { range, 14-68) }\end{array}$ \\
\hline Male: Female & $14: 8$ & 14:22 \\
\hline \multicolumn{3}{|l|}{ Anatomical distribution } \\
\hline Parotid gland & $20(91 \%)^{\mathrm{a}}$ & $35(97 \%)$ \\
\hline Minor salivary gland & $1(5 \%)^{\mathrm{a}}$ & $1(3 \%)$ \\
\hline Submandibular gland & $1(5 \%)^{\mathrm{a}}$ & 0 \\
\hline Median tumor size $(\mathrm{cm})$ & $\begin{array}{l}2.2 \text { (mean, } 2.3 ; \\
\text { range: } 1.1-3.8 \text { ) }\end{array}$ & $\begin{array}{l}2.7 \text { (mean, } 2.5 ; \\
\text { range, 1.0-5.2) }\end{array}$ \\
\hline \multicolumn{3}{|l|}{ Surgery } \\
\hline Superficial parotidectomy & $13(59 \%)$ & $22(61 \%)$ \\
\hline Total parotidectomy & $7(32 \%)$ & $13(36 \%)$ \\
\hline Mass excision & $2(9 \%)$ & $1(3 \%)$ \\
\hline \multicolumn{3}{|l|}{ Lymph-node dissection } \\
\hline Performed & $11(50 \%)$ & $5(14 \%)$ \\
\hline Not performed & $11(50 \%)$ & $31(86 \%)$ \\
\hline Nodal metastasis ${ }^{\mathrm{b}}$ & 4 out of 11 & 0 out of 5 \\
\hline Resection margin involvement & $2(9 \%)$ & $3(8 \%)$ \\
\hline \multicolumn{3}{|c|}{ American Joint Committee on Cancer tumor stage } \\
\hline I (T1N0) & $3(14 \%)^{\mathrm{c}}$ & $12(33 \%)^{\mathrm{b}}$ \\
\hline II (T2N0) & $14(64 \%)^{\mathrm{c}}$ & $21(58 \%)^{\mathrm{b}}$ \\
\hline III (T3 or N1) & $5(23 \%)^{\mathrm{c}}$ & $3(8 \%)^{\mathrm{b}}$ \\
\hline Post operative radiation therapy & $8(36 \%)$ & $5(14 \%)$ \\
\hline Median follow-up period (mo) & $\begin{array}{l}46 \text { (mean, 53.8; } \\
\text { range, 6-140) }\end{array}$ & $\begin{array}{l}48 \text { (mean, 58.5; } \\
\text { range, 6-180) }\end{array}$ \\
\hline Overall recurrence & $7(32 \%)$ & $5(14 \%)$ \\
\hline \multicolumn{3}{|l|}{ Recurrence site } \\
\hline Local & 5 & 3 \\
\hline Nodal & 1 & 0 \\
\hline Local and nodal & 1 & 2 \\
\hline Median recurrence interval (mo) & $\begin{array}{l}24 \text { (mean, 24.5; } \\
\text { range: 6-51) }\end{array}$ & $\begin{array}{l}48 \text { (mean, } 46 ; \\
\text { range: } 12-96 \text { ) }\end{array}$ \\
\hline Mean disease-free survival (mo) & $\begin{array}{l}99(95 \% \mathrm{CI}, \\
74-123)\end{array}$ & $\begin{array}{l}153(95 \% \mathrm{CI} \\
128-177)\end{array}$ \\
\hline 3 -year recurrence rate ${ }^{e}$ & $5 / 18(28 \%)$ & $2 / 26(8 \%)$ \\
\hline 5 -year recurrence rate ${ }^{e}$ & $7 / 16(44 \%)$ & $4 / 17(24 \%)$ \\
\hline Died of disease & $0(0 \%)$ & $0(0 \%)$ \\
\hline
\end{tabular}

${ }^{\mathrm{a}}$ The percentages before rounding are $90.9 \%, 4.5 \%$, and $4.5 \%$, respectively

${ }^{\mathrm{b}}$ Lymph-node metastasis was known only among cases undergoing lymph node dissection. To avoid overestimation, the percentage was not presented in this table

${ }^{\mathrm{c}}$ The percentages before rounding are $13.6 \%, 63.6 \%$, and $22.7 \%$, respectively. In 11 patients without node dissection, clinical $\mathrm{N}$ stage was considered as $\mathrm{cNO}$

${ }^{\mathrm{d}}$ The percentages before rounding are $33.33 \%, 58.33 \%$, and $8.33 \%$, respectively

${ }^{\mathrm{e}}$ Three-year and five-year follow-up data were available for 18 and 16 patients with secretory carcinoma, respectively; and 26 and 17 patients with acinic cell carcinoma, respectively

many as $25 \%$ cases in literatures [2]. A previous report shows about $22 \%$ (4/18) of lymph node metastases among patients with secretory carcinoma. Although statistical significance was not determined when combining 
Fig. 3 Landscape of the genetic alterations identified by the targeted deep sequencing analysis for 20 secretory carcinomas.

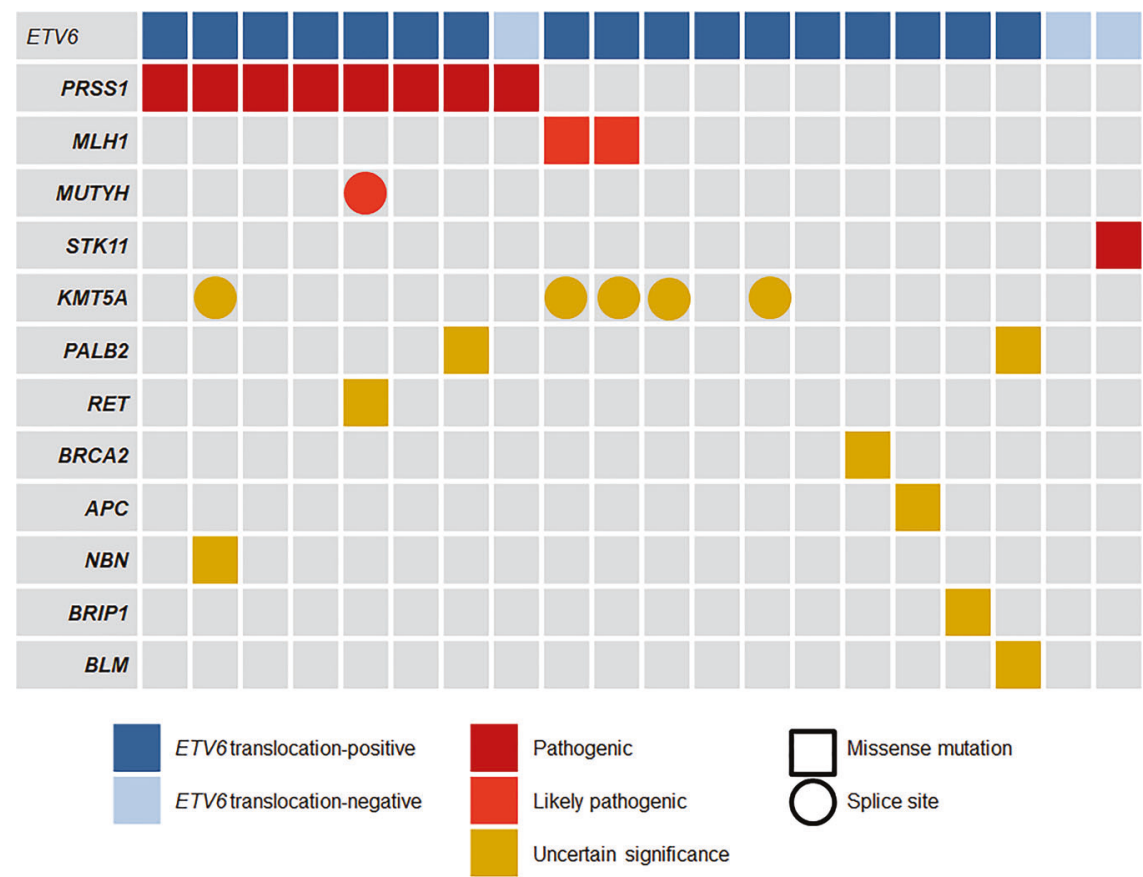

additional cases with known nodal status from previously reported cases, the proportion of secretory carcinoma cases with nodal metastasis $(17.6 \%, 6 / 34)$ remained slightly higher than acinic cell carcinoma $(3 / 38,7.9 \%)[4,16]$. These findings suggest the need for greater attention to neck lymph node metastasis in the treatment of patients with secretory carcinoma, including the surgical evaluation of lymph nodes. Furthermore, the aggressive clinical course in some secretory carcinoma cases like as tumor recurrence as shown in our series and other literatures $[1,2,4,16-18]$ suggests that secretory carcinoma may require risk stratification for patient treatment, despite the possibility of secretory carcinoma being a low-grade salivary gland carcinoma like acinic cell carcinoma. Histologically, we found the differential characteristics of secretory carcinoma to be the papillary cystic growth pattern, the lack of $\mathrm{PAS}^{+}$zymogen granules, and the distinct immunohistochemical profiles of S100 and/or mammaglobin positivity as well as DOG1 negativity, as previously described $[2,4-15,21,38]$.

The comprehensive targeted deep sequencing analyses of the secretory carcinoma cases were performed using cancerrelated gene panels. These analyses revealed novel recurrent somatic mutations, especially in the PRSS1 gene. Furthermore, our analyses provided biologic insight into genetic alterations of secretory carcinoma.

The PRSS1 gene encodes a cationic trypsinogen, which is a member of the trypsin family of serine proteases. This enzyme, which aids in digestion, is secreted by the pancreas and cleaved to its active form in the small intestine.
Germline and somatic mutations in the PRSS1 gene are associated with hereditary pancreatitis, chronic pancreatitis, and pancreatic adenocarcinoma. As a result of PRSS1 gene mutations, trypsinogen is prematurely activated and cannot be broken down because of the elimination of the trypsin hydrolysis site. The resulting increase in trypsin is thought to be associated with pancreatitis and pancreatic adenocarcinoma. The $\mathrm{R} 117 \mathrm{H}$ mutation is a frequently observed germline mutation in PRSS1. N29I, A16V, D22G, K23R, A121T, and R122C mutations in the PRSS1 gene have also been reported to be rare mutations in cationic trypsinogen [39-43]. Among these mutations, we recurrently observed the $\mathrm{A} 16 \mathrm{~V}(\mathrm{C} \rightarrow \mathrm{T})$ mutation in $40 \%(8 / 20)$ of secretory carcinoma cases. It may be the first identification of this mutation in secretory carcinoma.

Pancreatic digestive enzymes, including trypsin, are also expressed in salivary glands. Because both the pancreas and salivary glands are exocrine glands with a very similar histology [44, 45], the PRSS1 mutation and resulting abnormal trypsinogen function may also be involved in the pathogenesis of salivary gland cancer. The identification of a recurrent A16V mutation in the PRSS1 gene in secretory carcinoma is of clinical interest and warrants further in-depth studies as well in other subtypes of salivary gland tumors.

Secretory carcinoma is most commonly reclassified from zymogen granule-poor acinic cell carcinoma. Given that zymogen granules contain many digestive enzymes, such as trypsin, mutant PRSS1 may be involved in the tumorigenesis of this zymogen granule-poor cancer. ETV6-NTRK3 fusion may be associated with a secondary mutation in 
Fig. 4 The genetic alteration status between the case group with aggressive

clinicopathologic features, such as tumor recurrence, lymph node, and/or advanced American Joint Committee on Cancer stage III, and the case group of indolent features showing no evidence of tumor recurrence, lymph node metastasis, or advanced American Joint Committee on Cancer stage III.

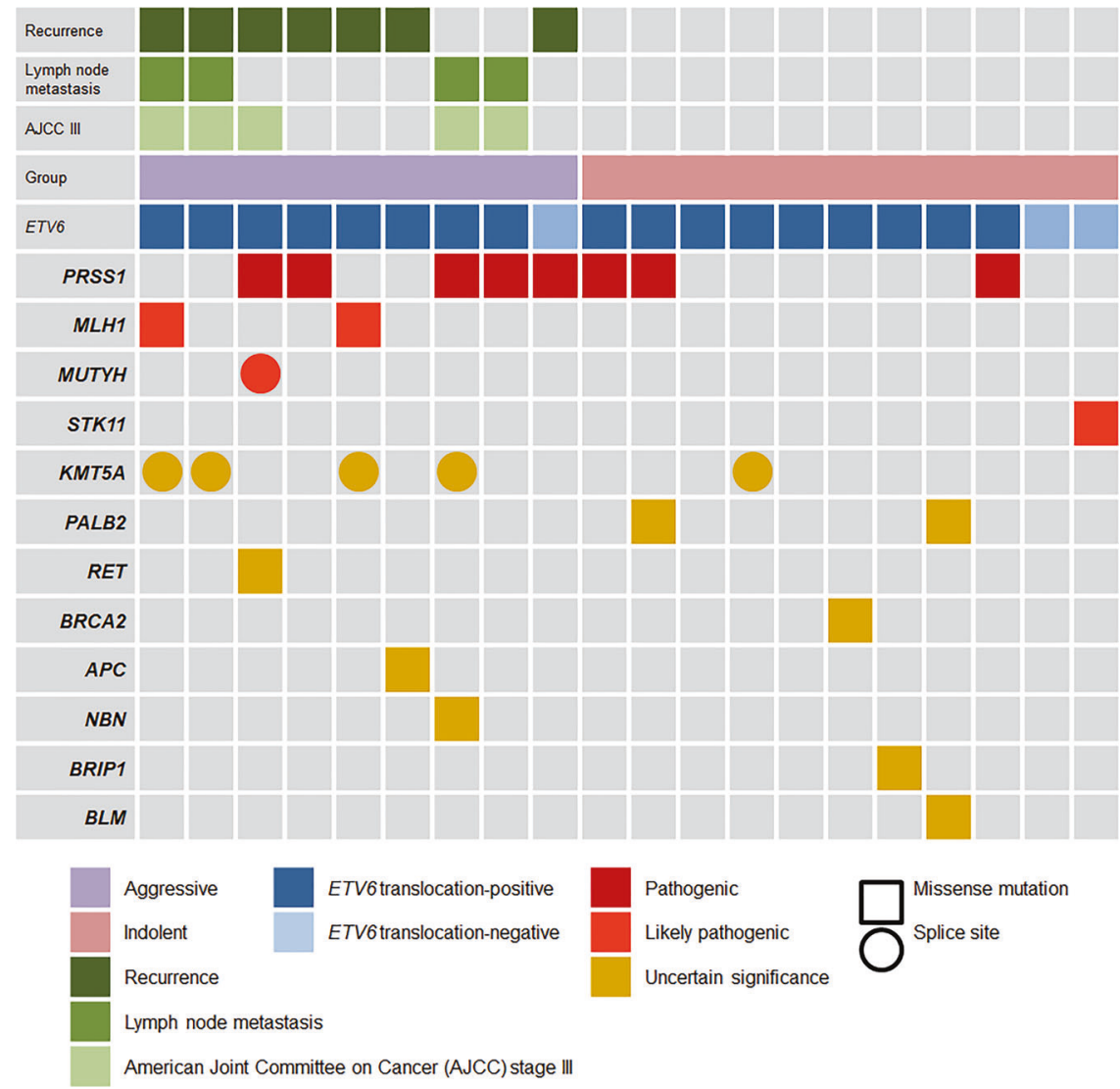

PRSS1, as secretory carcinoma is characterized by ETV6 gene rearrangement, with its most common translocation partner being the NTRK3 gene. There have been no studies on the relationship between PRSS1, ETV6 (a transcription repressor), and NTRK3 (a neurotropic tyrosine kinase). However, in our series, 1 case of SC with an intact ETV6 gene had the PRSS1 mutation, suggesting that other mechanisms may be involved in the PRSS1 mutation of zymogen granule-poor cancers.

Genetic profiling showed that the secretory carcinomas with intact ETV6 genes had genetic alterations that were not significantly different from those of the secretory carcinomas with ETV6 gene translocation. In addition, the PRSS1 mutation was shared by both. Therefore, the typical histology of secretory carcinoma, including the papillary cystic and microcystic growth pattern, the lack of $\mathrm{PAS}^{+}$zymogen granules, and the distinct immunohistochemical profiles of S100 and/or mammaglobin positivity [2, 4-15, 21, 38] supported the diagnosis of secretory carcinoma.

The 3 ETV6 translocation-negative secretory carcinomas originally diagnosed as zymogen granule-poor acinic cell carcinoma posed a diagnostic dilemma. The International Head and Neck Scientific Group recently proposed classifying these tumors as a family of tumors rather than distinct entities, such as carcinomas of intercalated duct-like cells in microcystic, papillary follicular, cystic, and mixed architectural arrangement among the acinic-intercalated ductal carcinoma [38]. In our series, however, we followed the current suggestion [20] and grouped the 3 ETV6 translocation-negative cases as secretory carcinoma.

Detection of ETV6 by FISH is technically feasible and has been described in most cases of secretory carcinoma since its original description. However, there were several reports showing that FISH did not detect ETV6 translocation in 5 to $14 \%$ of tested cases with typical histological features of secretory carcinoma $[10,17,20]$. In our series, $14 \%(3 / 22)$ of secretory carcinomas failed to detect ETV6 translocation by FISH analyses, and RNA fusion gene analyses also did not detect ETV6 gene fusion in those 3 cases. The negative results of ETV6 translocation by FISH analysis may stem from technical limits.

Secretory carcinoma did not display highly diverse or highly frequent pathogenic variants that are known to be cancer genomes in highly malignant human cancers [46]. Rather, the low-grade, indolent behaviors of secretory carcinoma were observed. Nevertheless, cases with aggressive clinicopathologic features, such as lymph node metastasis, advanced American Joint Committee on Cancer stage, and tumor recurrence, revealed some gene alterations of PRSS1, $M L H 1, M U T Y H$, and KMT5A. These gene alterations may 
help to classify the high risk group among patients diagnosed with secretory carcinoma.

A recent study has shown alternative ETV6 partners, such as RET and MAML3, by using the targeted nextgeneration sequencing assay [47]. Other studies have shown ETV6-RET fusion by using reverse transcription polymerase chain reaction [48]. Due to the low quality of RNA in our series, we could not reliably identify fusion scripts. We only observed the ETV6-NTRK3 fusion and the prototypical fusion in secretory carcinoma [1, 2]. The fusion was observed in 4 of ETV6 translocation-positive secretory carcinoma, but not any of ETV6 translocation-negative secretory carcinomas. As alternative fusion partners, NTRK2, ABL1, and PAX5 were also identified, but the read depth was too low and unreliable.

In addition to the ETV6 gene rearrangement, the A16V mutation in PRSS1 was recurrently observed in secretory carcinoma, which are generally low-grade indolent tumors. However, cases with aggressive clinicopathologic features have some recurrent gene alterations in PRSS1, MLH1, $M U T Y H$, and KMT5A. Regarding their distinct clinical and histological features, including relatively frequent rates of lymph node metastasis and tumor recurrence, these novel genetic alterations may provide insight into the biological pathogenesis of secretory carcinoma. They may also help to improve current diagnostic methods, patient treatment strategies, such as lymph node evaluation and follow-up for tumor recurrence, clinical risk stratification of patients, and therapeutic targets for recurrent intractable tumors.

Acknowledgements This study was supported by a faculty research grant from Yonsei University College of Medicine (grant number 62018-0065). We thank Paul Fletcher and Daley Drucker (H Lee Moffitt Cancer Center and Research Institute) for editorial assistance.

\section{Compliance with ethical standards}

Conflict of interest The authors declare that they have no conflict of interest.

Publisher's note Springer Nature remains neutral with regard to jurisdictional claims in published maps and institutional affiliations.

Open Access This article is licensed under a Creative Commons Attribution 4.0 International License, which permits use, sharing, adaptation, distribution and reproduction in any medium or format, as long as you give appropriate credit to the original author(s) and the source, provide a link to the Creative Commons license, and indicate if changes were made. The images or other third party material in this article are included in the article's Creative Commons license, unless indicated otherwise in a credit line to the material. If material is not included in the article's Creative Commons license and your intended use is not permitted by statutory regulation or exceeds the permitted use, you will need to obtain permission directly from the copyright holder. To view a copy of this license, visit http://creativecommons. org/licenses/by/4.0/.

\section{References}

1. Skalova A, Vanecek T, Sima R, et al. Mammary analogue secretory carcinoma of salivary glands, containing the ETV6NTRK3 fusion gene: a hitherto undescribed salivary gland tumor entity. Am J Surg Pathol. 2010;34:599-608.

2. Skalova A, Bell D, Bishop JA, Inagaki H, Seethala R, Vielh P. Tumours of salivary glands. In: El-Naggar AK, editor. WHO classification of head and neck tumours. 4th ed. Lyon: International Agency for Research on Cancer; 2017. p. 177-8.

3. Gatalica Z, Xiu J, Swensen J, Vranic S. Molecular characterization of cancers with NTRK gene fusions. Mod Pathol. 2019;32: 147-53.

4. Chiosea SI, Griffith C, Assaad A, Seethala RR. Clinicopathological characterization of mammary analogue secretory carcinoma of salivary glands. Histopathology. 2012;61:387-94.

5. Pinto A, Nose V, Rojas C, Fan YS, Gomez-Fernandez C. Searching for mammary analogue [corrected] secretory carcinoma of salivary gland among its mimics. Mod Pathol. 2014;27:30-7.

6. Hsieh MS, Chou YH, Yeh SJ, Chang YL. Papillary-cystic pattern is characteristic in mammary analogue secretory carcinomas but is rarely observed in acinic cell carcinomas of the salivary gland. Virchows Arch. 2015;467:145-53.

7. Luk PP, Selinger CI, Eviston TJ, et al. Mammary analogue secretory carcinoma: an evaluation of its clinicopathological and genetic characteristics. Pathology. 2015;47:659-66.

8. Stevens TM, Kovalovsky AO, Velosa C, et al. Mammary analog secretory carcinoma, low-grade salivary duct carcinoma, and mimickers: a comparative study. Mod Pathol. 2015;28:1084-100.

9. Urano M, Nagao T, Miyabe S, et al. Characterization of mammary analogue secretory carcinoma of the salivary gland: discrimination from its mimics by the presence of the ETV6-NTRK3 translocation and novel surrogate markers. Hum Pathol. 2015;46:94-103.

10. Din NU, Fatima S, Kayani N. Mammary analogue secretory carcinoma of salivary glands: a clinicopathologic study of 11 cases. Ann Diagn Pathol. 2016;22:49-53.

11. Baghai F, Yazdani F, Etebarian A, Garajei A, Skalova A. Clinicopathologic and molecular characterization of mammary analogue secretory carcinoma of salivary gland origin. Pathol Res Pract. 2017;213:1112-8.

12. Bissinger O, Gotz C, Kolk A, et al. Mammary analogue secretory carcinoma of salivary glands: diagnostic pitfall with distinct immunohistochemical profile and molecular features. Rare Tumors. 2017;9:7162.

13. Hindocha N, Wilson MH, Pring M, Hughes CW, Thomas SJ. Mammary analogue secretory carcinoma of the salivary glands: a diagnostic dilemma. Br J Oral Maxillofac Surg. 2017;55:290-2.

14. Said-Al-Naief N, Carlos R, Vance GH, Miller C, Edwards PC. Combined DOG1 and mammaglobin immunohistochemistry is comparable to ETV6-breakapart analysis for differentiating between papillary cystic variants of acinic cell carcinoma and mammary analogue secretory carcinoma. Int J Surg Pathol. 2017;25:127-40.

15. Thompson LD, Wenig BM. Diagnostic pathology: head and neck. 2nd ed. Salt Lake City, UT: Elsevier, Inc; 2016.

16. Sethi R, Kozin E, Remenschneider A, et al. Mammary analogue secretory carcinoma: update on a new diagnosis of salivary gland malignancy. Laryngoscope. 2014;124:188-95.

17. Majewska H, Skalova A, Stodulski D, et al. Mammary analogue secretory carcinoma of salivary glands: a new entity associated with ETV6 gene rearrangement. Virchows Arch. 2015;466: 245-54.

18. Jung MJ, Song JS, Kim SY, et al. Finding and characterizing mammary analogue secretorycarcinoma of the salivary gland. Korean J Pathol. 2013;47:36-43. 
19. Amin MB, Edge SB, Greene FL, et al. AJCC cancer staging manual. 8th ed. Chicago IL: American Joint Committee on Cancer, Springer; 2017. p. 95-101.

20. Shah AA, Wenig BM, LeGallo RD, Mills SE, Stelow EB. Morphology in conjunction with immunohistochemistry is sufficient for the diagnosis of mammary analogue secretory carcinoma. Head Neck Pathol. 2015;9:85-95.

21. Woo HY, Choi EC, Yoon SO. Diagnostic approaches for salivary gland tumors with secretory and microcystic features. Head Neck Pathol. 2018;12:237-43.

22. Bishop JA, Yonescu R, Batista DA, Westra WH, Ali SZ. Cytopathologic features of mammary analogue secretory carcinoma. Cancer Cytopathol. 2013;121:228-33.

23. McKenna A, Hanna M, Banks E, et al. The genome analysis toolkit: a MapReduce framework for analyzing next-generation DNA sequencing data. Genome Res. 2010;20:1297-303.

24. Martin M. Cutadapt removes adapter sequences from highthroughput sequencing reads. EMBnet J. 2011;17:10-2.

25. Li H, Durbin R. Fast and accurate long-read alignment with Burrows-Wheeler transform. Bioinformatics. 2010;26:589-95.

26. Li H, Handsaker B, Wysoker A, et al. The sequence alignment/ map format and SAMtools. Bioinformatics. 2009;25:2078-9.

27. Cibulskis K, Lawrence MS, Carter SL, et al. Sensitive detection of somatic point mutations in impure and heterogeneous cancer samples. Nat Biotechnol. 2013;31:213.

28. Lek M, Karczewski KJ, Minikel EV, et al. Analysis of proteincoding genetic variation in 60,706 humans. Nature. 2016;536:285.

29. Cingolani P, Platts A, Wang LL, et al. A program for annotating and predicting the effects of single nucleotide polymorphisms, SnpEff. Fly. 2012;6:80-92.

30. Cingolani P, Patel VM, Coon $\mathrm{M}$, et al. Using Drosophila melanogaster as a model for genotoxic chemical mutational studies with a new program, SnpSift. Front Genet. 2012;3:35.

31. Liu X, Wu C, Li C, Boerwinkle E. dbNSFPv3.0: a one-stop database of functional predictions and annotations for human nonsynonymous and splice-site SNVs. Hum Mutat. 2016;37:235-41.

32. Sherry ST, Ward M-H, Kholodov M, et al. dbSNP: the NCBI database of genetic variation. Nucleic Acids Res. 2001;29:308-11.

33. Robinson JT, Thorvaldsdóttir H, Winckler W, et al. Integrative genomics viewer. Nat Biotechnol. 2011;29:24.

34. Layer RM, Chiang C, Quinlan AR, Hall IM. LUMPY: a probabilistic framework for structural variant discovery. Genome Biol. 2014;15:R84.
35. Millis SZ, Jardim DL, Albacker L, et al. Phosphatidylinositol 3 kinase pathway genomic alterations in 60,991 diverse solid tumors informs targeted therapy opportunities. Cancer. 2019;125: 1185-99.

36. Yurgelun MB, Kulke MH, Fuchs CS, et al. Cancer susceptibility gene mutations in individuals with colorectal cancer. J Clin Oncol. 2017;35:1086-95.

37. Li Z, Nie F, Wang S, Li L. Histone H4 Lys 20 monomethylation by histone methylase SET8 mediates Wnt target gene activation. Proc Natl Acad Sci USA. 2011;108:3116-23.

38. Vander Poorten V, Triantafyllou A, Thompson LD, et al. Salivary acinic cell carcinoma: reappraisal and update. Eur Arch Otorhinolaryngol. 2016;273:3511-31.

39. Sikdar N, Saha G, Dutta A, et al. Genetic alterations of periampullary and pancreatic ductal adenocarcinoma: an overview. Curr Genomics. 2018;19:444-63.

40. Whitcomb DC, Gorry MC, Preston RA, et al. Hereditary pancreatitis is caused by a mutation in the cationic trypsinogen gene. Nat Genet. 1996;14:141-5.

41. Kereszturi E, Szmola R, Kukor Z, et al. Hereditary pancreatitis caused by mutation-induced misfolding of human cationic trypsinogen: a novel disease mechanism. Hum Mutat. 2009;30: 575-82.

42. Rustgi AK. Familial pancreatic cancer: genetic advances. Genes Dev. 2014;28:1-7.

43. Yi Q, Dong F, Lin L, et al. PRSS1 mutations and the proteinase/ antiproteinase imbalance in the pathogenesis of pancreatic cancer. Tumour Biol. 2016;37:5805-10.

44. Terada T, Kitamura Y, Ashida K, et al. Expression of pancreatic digestive enzymes in normal and pathologic epithelial cells of the human gastrointestinal system. Virchows Arch. 1997;431: 195-203.

45. Mills S. Histology for pathologists. 5th ed. Philadelphia PA: Lippincott Williams \& Wilkins; 2019.

46. Vogelstein B, Papadopoulos N, Velculescu VE, et al. Cancer genome landscapes. Science. 2013;339:1546-58.

47. Guilmette J, Dias-Santagata D, Nose V, Lennerz JK, Sadow PM. Novel gene fusions in secretory carcinoma of the salivary glands: enlarging the ETV6 family. Hum Pathol. 2019;83:50-8.

48. Skalova A, Vanecek T, Martinek P, et al. Molecular profiling of mammary analog secretory carcinoma revealed a subset of tumors harboring a novel ETV6-RET translocation: report of 10 cases. Am J Surg Pathol. 2018;42:234-46. 